Acta Universitatis Wratislaviensis

No 3726

Anglica Wratislaviensia LIV

Wrocław 2016

DOI: $10.19195 / 0301-7966.54 .5$

Krzysztof Hwaszcz

University of Wrocław

\title{
An L2 Study on the Production and Perception of Stress Patterns in English: Second Language Acquisition of Compound Words
}

\begin{abstract}
As compounding in English is a very productive process, a number of constructions emerged which can have multiple meanings. This paper aims to investigate the extent to which promiscuous compound nouns can be problematic for L2 English learners. The central questions which are addressed here are as follows: (i) What strategies do Polish speakers use to overcome the production and comprehension difficulties when processing English compounds? (ii) To what extent can Polish learners acquire the ability to produce and comprehend English compounds effectively? We compare the production and perception of stress patterns in various types of English compounds by L1 and L2 speakers of English on the basis of a reading protocol and a lexical decision experiment. One of the striking observations is that L1s are not always more accurate than L2s. This concerns stress-recognition in Adjective-Noun $(\mathrm{A}-\mathrm{N})$ phrases (which are juxtaposed with $\mathrm{A}-\mathrm{N}$ compounds). Elsewhere, natives lead in terms of stress-placement. On the other hand, the results obtained by L1s show no difference in stress-production and stress-recognition in Noun-Noun $(\mathrm{N}-\mathrm{N})$ attributive compounds, whereas $\mathrm{L} 2 \mathrm{~s}$ are more accurate in understanding than producing this type of compounds. A similar situation, in the case of $\mathrm{L} 1 \mathrm{~s}$, concerns $\mathrm{A}-\mathrm{N}$ opaque and $\mathrm{N}-\mathrm{N}$ argument-head compounds but it is less prominent. As for $\mathrm{L} 2 \mathrm{~s}, \mathrm{~A}-\mathrm{N}$ opaque compounds elicit relatively comparable results, but $\mathrm{N}-\mathrm{N}$ argument-head compounds are responded to more accurately in the production experiment. A-N phrases, on the other hand, elicit a huge disproportion of accuracy between production and perception among L1s: although almost flawless in production, two-thirds of responses are inaccurate in perception. As for non-natives, they are more or less equally accurate in the case of A-N opaque compounds (less than half correct renditions), but they adopt a strong tendency to produce and perceive fore-stress patterns across the board. Our experiments showed certain regularities in both accuracy and inaccuracy of stress placement by L2s. These regularities can be applied in methodology as to the order of teaching different types of compounds and phrases to Polish learners of English.
\end{abstract}

Keywords: second language acquisition (SLA); prosody; stress patterns; compound words; Polish community; production; perception; psycholinguistic evidence; L1 transfer 


\section{Introduction}

Compound words are a fascinating linguistic phenomenon because they are evident in the majority of word formation systems, among which are English and Polish. As demonstrated by their vitality and productivity, compounds constitute an intrinsic element in language spoken by natives and thus they are significant in the process of teaching and learning. This work is targeted at foreign language teachers as well as those who crave for the proficiency in a command of English.

This paper is devoted to one specific property of English compound words: their stress pattern, which is frequently unsystematic and thus poses a number of problems for L2 English learners. First, we present observations on some (but limited) regularity of stress patterns in English compounds, which can be somehow attributed to such factors as semantic transparency and attributiveness. Next, we argue that: (i) compounds in Polish exhibit a full regularity of stress patterns and show that this property of the Polish language phonetics may influence the processing of English compound words by L2s; (ii) the strategies used to distinguish compounds from phrases by L1s and L2s are similar. Then, we present a pilot study on the production and perception of stress patterns in different types of compound words as well as phrases. The testees who participated in the experiments were English natives and L2 English learners. We compare the outcomes of the two experiments and address the question of whether Polish speakers have the capability of acquiring the combinatorial algorithm that governs the stress patterns in English compounds.

The present paper is constructed as follows: in section 2 we provide some theoretical background on the syntactic analysis of English and Polish compound words as well as on SLA of stress and accent; in section 3 we present our study and the results of the conducted experiments; in section 4 we draw some essential conclusions.

\section{Background}

Analysing the notion of prosody with regard to semantic transparency is a hopeful attempt at understanding the role of analogy in acquiring the ability to produce and understand English compound words by L2 learners (see Almbark, Bouchhioua and Hellmuth 2014 or Zubizarreta, He and Jonckheere 2013). Let us first briefly outline the notion of semantic transparency: in contrast to semantic opacity, it means that the meaning of the whole compound is collectively related to the meaning of its constituents (e.g., blúeberry). Semantic opacity can be classified into three fundamental degrees with regard to the semantic relations between the constituents: (i) TO (transparent-opaque), e.g., blúebell; (ii) OT (opaque-transparent), e.g., gréenhouse; (iii) $\mathrm{OO}$ (opaque-opaque), e.g., blúebottle (denoting a jellyfish 
of a sort). As can be noted, stress shift is not overtly manifested by the opacity of the constituents (for example, it is not the case that transparent constituents are stressed and that opaque ones are not). However, there is indeed some sort of covert relation, which we discuss below.

Prosody manifests itself in the stress-pattern that is fixed to certain constructions. The stress cannot be freely changed without consequences for syntax and/or semantics. The shift in stress placement is a rare phenomenon and it influences the syntactic properties of stress-doublets: a transition from a compound to a phrase (e.g., blúebottle - blue bóttle) or from a compound to another compound (e.g., tóy-factory - toy-fáctory). Giegerich (2006) discusses in detail the properties of English N-N compounds and A-N compounds/phrases that are stress-doublets (e.g., $\mathrm{N}-\mathrm{N}$ : wóman-doctor vs. woman-dóctor, A-N: gréenhouse vs. green hóuse) and challenges various theoretical accounts (see Bauer 1998; Jespersen 1942; Marchand 1969; Olsen 2001) which postulate the correlation between the categorial status (lexical vs. syntactic) of particular combinations and their stress pattern. He argues extensively that neither end-stressed items nor semantically transparent collocations necessarily have phrasal nature. Consequently, the distribution of fore-stress and end-stress is far from regular, and clearly independent from lexicalization, at least in the sense that end-stress does not necessarily indicate phrasal status. Moreover, he notes a general tendency of fore-stress in the production of all these collocations. Giegerich argues that both modules (the syntactic and the lexical) can produce the semantic relationship of attributiveness, that semantic opacity is disconnected from the syntax and that fore-stress is connected to the lexicon. The above observations made by Giegerich indicate that both semantic transparency and end-stress can be observed in the lexicon. As a consequence, the categorial distinction between English words and phrases is rather fuzzy. On the other hand, El-Bialy et al. (2013) postulate that semantic transparency of compounds influence their processing. They found, by means of semantic priming, that pre-activation of a non-head's meaning is beneficial for fully transparent and fully opaque compounds, but not for partially opaque ones. El-Bialy et al. (2013) argue that semantic transparency emerges as a result of differences in processing, not in representation, which seems to be compatible with Giegerich's proposal.

A number of studies on SLA of accent provide theoretical and empirical evidence of L1 stress-transfer effects in terms of accentuating words in L2 according to the rules of L1 (e.g., Archibald 1994; 1997 or Ghazali and Bouchhioua 2003). In light of this remark, let us now compare the syntactic and prosodic features of compounds in English and Polish.

In the English language, which exhibits different stress patterns in various compound words, it is problematic to find general principles that would be applicable across the board. The famous examples, provided by Giegerich (2006), Mádison Street (fore-stressed) and Madison Ávenue (end-stressed), lead to a conclusion 
that the end-stress/fore-stress distinction is not at all clear-cut because the constructions in question are practically identical in terms of semantics and syntax, and yet fundamentally different in terms of phonology. The end-stress pattern does not indicate that the construction is solely of a phrasal type; conversely, the fore-stress pattern does not necessarily characterize compounds exclusively (i.e., whereas súnfloweroil or córnoil, due to their fore-stress pattern, may be successfully interpreted as compounds, olive óil, with its end-stress pattern, following the overgeneralized rule that compounds are only fore-stressed, should not be analysed as such). It can be assumed, therefore, that attributive ${ }^{1}$ constructions may become lexicalized (with or without any change in form and/or meaning) and that they may further evolve into non-attributive constructions, whose meanings are more lexicalized. This process is not a general principle, although such transition may occur as a result of repetitive usage of a particular phrase. The attribute-head constructions thus reflect some kind of competition between the lexicon and the syntax. In some types of constructions there is an unclear distinction between a phrase and a compound, just as there is an unclear distinction between the lexicon and the syntax. And just as there is only a vaguely outlined border between the lexicon and the syntax, the distinction between attribute-head compounds and phrases is equally so.

In the Polish language, the majority of compound words are written as one word (so-called solid compounds) and the stress pattern is relatively invariable: most words ${ }^{2}$ receive a single stress on the penultimate syllable. As is evidenced by Szymanek (2012), the compound/phrase distinction in Polish is frequently easily detectable by means of their stress patterns (in accordance with the regular word stress): e.g., compare a compound dobránoc 'good night' and a phrase dobra nóc 'a good night'. Nominal compounds, upon which we concentrate in this paper, can be divided in Polish into three major groups according to the manner of linking the lexemes: (i) with an intra-compound spacing (so-called juxtapositions, e.g., panna młóda 'a bride' or niedźwiedź polárny 'the polar bear'); (ii) with an interfix or intermorph, otherwise known as a linking vowel, such as -o- (e.g., gwiazd-ó-zbiór 'a constellation' or star-ó-druk 'an antique book'); or (iii) with no presence of the intermorph (e.g., okamgniénie 'a moment'). In the last group, the ending $-a$ marks an inflectional desinence governed by the rules of Polish grammar - the genitive singular of the noun ok(o) 'eye' (for clarity, cf. okamgniénie 'a blink of an eye'), thus should not be treated as an intermorph. Groups

${ }^{1}$ When compounds are attributive, the relation between their components is is or is associated with, e.g.: boy actor $\rightarrow$ 'an actor who is a boy' or morning coffee $\rightarrow$ 'a coffee which is associated with morning'.

2 There are certain groups of words in Polish, usually verbs in the conditional mood and some nominal borrowings, that receive a stress on the antepenultimate syllable (e.g., fízyka 'physics' or úcichłby 'would go quiet- MASC.SG'). 
(ii) and (iii) exhibit the same stress pattern as most Polish monomorphemic words do, and this is a Polish-specific property. However, group (i), in which both elements are stressed, exhibits a similar stress pattern as syntactic phrases, which is a property also evident in English compounds/phrases. Therefore, we compare Polish juxtapositions in (i) with English compounds with regard to stress pattern and head placement.

As far as Polish A-N compound words are concerned, they may appear in both orders, i.e., $\mathrm{A}-\mathrm{N}$ and $\mathrm{N}-\mathrm{A}$, depending on the semantic relation between the constituents. Both compound and phrasal stress is always on the rightmost constituent (Anusiewicz 2010: 52). Most of those collocations are head-final, e.g., zlota $_{[\mathrm{A}]}$ ráczka $a_{[\mathrm{N}]}$ 'handyman'; however, head-initial ones, though rare, can also be found, e.g., panna $a_{[\mathrm{N}]} m \nmid o ́ d a_{[\mathrm{A}]}$. In the two examples, raczka and panna are nouns which function as the head. Surprisingly, only N-A compounds have their corresponding parallel structures, which vary in the order of the constituents (and in meaning). For example, in addition to the fixed, listed, opaque collocation panna $a_{[\mathrm{N}]} m t o ́ d a_{[\mathrm{A}]}$ 'bride', there is a phrase $m \nmid o d a_{[\mathrm{A}]}$ pánna $_{[\mathrm{N}]}$ 'young lady'. The stress is always on the rightmost constituent, so on the head in $\mathrm{A}-\mathrm{N}$ phrases with attributive relation, or on the non-head in non-attributive $\mathrm{N}-\mathrm{A}$ juxtapositions. Thus, we can observe a correlation between Polish and English (cf. a noun stressed in phrases: młoda pánna vs. blue bóttle, an adjective stressed in compounds: panna młóda vs. blúebottle). The difference between the two languages lies in the word order: in Polish the components swap places and in English they do not.

The majority of studies devoted to SLA investigated the acquisition of the phonology of stress rather than of the phonetic realization of stress. According to the study conducted by Flege and Bohn (1989) on Swedish L2 learners with the use of stress-doublets in English, the acquisition of phonological stress placement (investigated by means of auditory analysis) is less problematic than the acquisition of phonetic realization (investigated by means of acoustic analysis). Some studies found evidence of L1 transfer effect in stress placement (e.g., Nava and Zubizarreta 2008), whereas others associate such patterns with user-specific intonation properties (e.g., Mennen, Chen and Karlsson 2010).

\section{Our study}

In our study, we investigate the factors that influence the acquisition of stress patterns of compound words with the use of A-N and N-N stress-doublets. Such constructs are of special interest in the study of SLA because we can both register the stress placement across various compound types, and observe the analogy adopted by individual L2 speakers for left- and right-hand stressed collocations. The constructs used in our experiments are listed in (1-2) below: 
1) semantically transparent collocations:

a) $\mathrm{N}-\mathrm{N}$ compounds with attributive relation, i.e., the 'is a' relation with respect to the head (end-stressed)

woman-doctor, toy-factory, apprentice-welder, man-killer, robot-mechanic, dragon-healer, glass-case, paper-bag, steel-warehouse, iron-crate;

b) N-N compounds with argument-head relation (fore-stressed)

French-teacher, woman-doctor, toy-factory, apprentice-welder, man-killer, robot-mechanic, dragon-healer, glass-case, paper-bag, steel-warehouse, iron-crate, metal-box (for the last five examples expressing "contains" relation, cf. Zubizaretta et al., 2011);

c) fully compositional A-N phrases with attributive relation (end-stressed)

French teacher, black bird, blue bottle, green house, red wood, blue bell, red eye, green horn, metal box, plastic money;

2) semantically opaque A-N compound words (fore-stressed)

blackbird (TO), bluebottle (TO), redwood (TO), bluebell (TO), plastic money (TO), greenhouse (OT), red-eye (OO), greenhorn $(\mathrm{OO})$.

The issue of analogy, mentioned first at the beginning of this paper, is based on the observations made in section 2 - namely, that in the case of attributive constructs, L2 English learners are expected to be more accurate than in the case of non-attributive constructs (because of the cross-linguistic similarity manifested in placing end-stress). In order to explain the possible role of analogy in acquiring stress patterns in compounds, we conducted two experiments: production and perception. The production part was a reading protocol - a task which gauged the stress pattern in English collocations, whereas the perception part was a lexical decision task which measured the stress pattern and the response time for the token items. The same testees have been involved in both experiments: 25 Polish/ L2s undergraduate students (aged 22-32) and 6 native speakers ${ }^{3}$ (aged 22-62) participated in the experiment. All of the L2s were students of English Philology who could be described as highly proficient in English.The detailed description of these experiments can be found below.

\subsection{Experiment 1: production}

In this experiment, two types of stress-doublets (1-2) were embedded in sentences which provided a clear context for one of the meanings. The stimuli consisted of 40 sentences containing the chosen compounds ( 20 with fore- and 20 with

${ }^{3} \mathrm{We}$ are aware that the number of L1s is nowhere near the statistical minimum to be significant. It should be borne in mind that it is a pilot study which needs certain re-evaluation. Nevertheless, the central problem in this paper concerns SLA, which is primarily tested among L2s, whose number is sufficient in this case. Also, the extensiveness of prosodic compound-related studies which employed L1s (e.g., Zubizarreta, 2013) allows for a procedure in which just a sample of L1s' data is collected to observe if it is compatible with the previous findings. 
end-stress), as well as of 20 filler sentences, which were similar in length to the target sentences so that they did not stand out from the rest. The target items were counterbalanced in a way that the participants were exposed to only one of the two possible items from the stress-doublets. The order of sentence presentation was randomized with an online sentence randomizer so that consecutive participants were not supposed to find the algorithm. One sentence at a time was presented on the screen, centred horizontally, with each successive sentence replacing the previous one. Each sentence's presentation duration was adjusted to individual participants (until they finished reading). The participants were instructed to read the sentences in silence and grasp the presented context before reading them out loud. The way they read out the sentences showed where they thought the stress within a compound should be placed. The data was recorded manually with the use of scientific software package for prosodic analysis called Praat. The exemplary sentences of two random pairs of stress-doublets (one $\mathrm{N}-\mathrm{N}$ and one $\mathrm{A}-\mathrm{N}$ ) are provided in (3-6) below.

3) It is predicted that in the future people will no longer have to care about their households as there will be a robot-mechanic that will take care of our household appliances. (robot-mechánic)

4) The company has placed an ad in the newspaper in which they wanted to hire a very experienced robot-mechanic as there are instances galore of malfunctions of their machinery. (róbot-mechanic)

5) Water is frequently sold in blue bottles as they make a lasting impression that the water is crystal clear and thirst-quenching. (blue bóttles)

6) One of the environmental pressures in the Great Barrier Reef includes cyclic population outbreaks of the bluebottles, which are a kind of jelly fish. (blúebottles)

fore-stressed compounds

(N-N: e.g., róbot-mechanic vs. A-N: e.g., blúebottle)

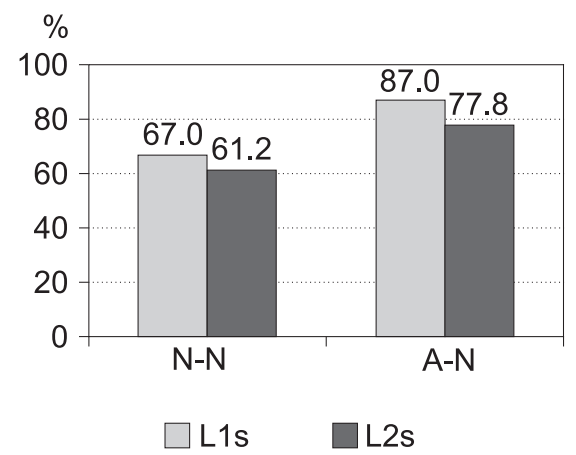

Figure 1. Proportion of fore-stress placement accuracy for fore-stressed compounds 
end-stressed compounds/phrases

(N-N: e.g., robot-mechánic vs. A-N: e.g., blue bóttle)



Figure 2. Proportion of end-stress placement accuracy for end-stressed compounds

We are mostly interested in the comparison of: (i) the accuracy of stress placement between L1s and L2s in each of the four collocations and (ii) the accuracy of stress placement within and across L2s. In the case of native speakers, A-N opaque compounds were responded to more accurately than $\mathrm{N}-\mathrm{N}$ non-attributive compounds (Figure 1). Also, A-N phrases triggered more correct renditions than $\mathrm{N}-\mathrm{N}$ attributive compounds (Figure 2). Turning now to non-natives, their production of correct stress patterns was generally more frequent in the case of $\mathrm{A}-\mathrm{N}$ than $\mathrm{N}-\mathrm{N}$ collocations. In fact, L2s produced more fore-stress patterns for each of the four collocations, which means that they are reluctant to place the stress on the rightmost constituent despite the fact that it is the case in all such collocations in Polish. It seems as if they wanted to sound different from their mother tongue, regardless of the collocation type. Similarly, L2s of Polish origin adopt a similar procedure in the case of the word computer which is stressed on the penultimate syllable both in Polish and English (komputer and computer) and yet Polish speakers tend to differentiate it from their native language by stressing incorrectly the first syllable (cómputer).

The above observations concern language output exclusively. Let us now turn to the issue of recognizing the stress patterns in promiscuous compounds/phrases among L2s.

\subsection{Experiment 2: perception}

In this experiment, two types of stress-doublets (the same as in Experiment 1) were presented in isolation, followed by two definitions. One of the definitions was true and the second one, defining their respective stress-counterparts, was not true (e.g., the oral presentation of stéel warehouse was followed by such two definitions: 'warehouse made of steel' and 'warehouse that contains steel'). The order of the two definitions was random. The lexical decision task was designed to gauge the stress identification and the reaction time (RT) of choosing the definition. 
The target items were counterbalanced so that the participants saw only one of the two possible items from the stress-doublets. It was necessary to place the perception experiment after the production part because the two definitions (i.e., different meanings) along with different stress patterns of the collocations revealed the very essence of the compound phenomenon, which we wanted to test in Experiment 1, i.e., that in English there exist stress-doublets which, because of their distinctive accentuation, carry different meanings. Had the subjects overtly realized this regularity before the production part, they would have taken more care of their renditions and therefore the results would not be reliable.

The perception experiment was conducted by means of PsychoPy software. There was a trial session to acquaint $\mathrm{L} 2 \mathrm{~s}$ with the rules of the experiment. The compounds were presented along with two possible meanings marked as 1) and 2). The definitions were taken from an online dictionary found on the website www. macmillandictionary.com. Once the participants heard the compound with fore or end-stress, they needed to press button 1 on the keyboard for the meaning presented in 1) and button 2 for the meaning presented in 2). The programme automatically measured the reaction times in the lexical decision task. The order of item presentation was automatically randomized with the software PsychoPy so that consecutive participants were not able to find the algorithm. One target item at a time was presented on the screen, centred horizontally, with each successive item replacing the previous one.

fore-stressed compounds

(N-N: e.g., róbot-mechanic vs. A-N: e.g., blúebottle)

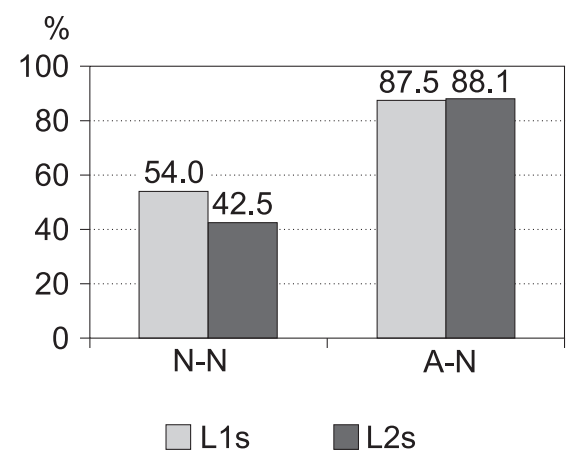

Figure 3. Proportion of fore-stress identification accuracy for fore-stressed compounds

Similarly to the production experiment, here we are mostly interested in the comparison of: (i) the accuracy of stress placement between L1s and L2s in each of the four collocations and (ii) the accuracy of stress placement within and across L2s. In the case of native speakers, fore-stressed A-N compounds were responded to more accurately than fore-stressed $\mathrm{N}-\mathrm{N}$ compounds (Figure 3 ). When it comes to end-stressed collocations, $\mathrm{N}-\mathrm{N}$ compounds triggered more accurate renditions than A-N phrases (Figure 4). 
end-stressed compounds/phrases

(N-N: e.g., robot-mechánic vs. A-N: e.g., blue bóttles)

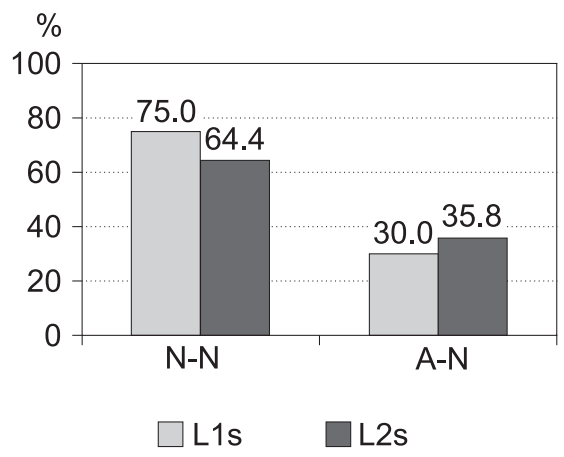

Figure 4. Proportion of fore-stress identification accuracy for end-stressed compounds/phrases

Turning now to L2s, their accuracy of identifying the stress patterns across A-N collocations was very similar to L1s, but slightly higher. Among fore-stressed compounds, the stress pattern in A-N was identified more accurately than in $\mathrm{N}-\mathrm{N}$; among end-stressed collocations, it is $\mathrm{N}-\mathrm{N}$ compounds which were responded to more accurately than $\mathrm{A}-\mathrm{N}$ phrases.

The analysis of the time spent on responding to particular constructs provides an insightful view of how quickly the four types of collocations in question are processed. As can be noted, there is a huge disproportion of response times between A-N and N-N collocations, for both fore- and end-stressed. Although predictable, but still worthy of attention, is the fact that L1s processed the token items faster than L2s

\subsection{Discussion}

We have so far outlined the most fundamental observations from the experiments at hand. This subsection is devoted to a discussion (and at least some explanation) about the number of questions that arise from the above data analysis. Some of the obtained results are puzzling and we do not know how to account for them. And yet we have selected several explicit issues which seem to be particularly apt for the study of SLA:

7) A-N compounds receive significantly better results in both experiments than $\mathrm{N}-\mathrm{N}$ compounds;

8) both L1s and L2s tend not to identify A-N phrases by their end-stress patterns although, following Giegerich (2006), this is the only construction type, among those studied here, which has a uniform stress pattern;

9) both L1s and L2s identify A-N compounds more accurately than $\mathrm{N}-\mathrm{N}$ compounds. 


\begin{tabular}{|c|c|c|c|c|c|c|c|c|c|c|c|c|c|c|}
\hline \multirow{6}{*}{ 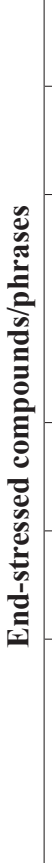 } & $\underline{\simeq}$ & $\underset{0}{\tilde{o}}$ & $\begin{array}{l}\vec{\infty} \\
i\end{array}$ & $\stackrel{\sim}{\sim}$ & $\stackrel{n}{m}$ & $\begin{array}{l}\infty \\
i \\
\sim\end{array}$ & $\stackrel{+}{\Delta}$ & ભે & ๗ે & $\stackrel{?}{\stackrel{9}{i}}$ & $\begin{array}{l}\infty \\
n \\
n\end{array}$ & & & $\ddot{\sim}$ \\
\hline & 急 & $\hat{\sigma}$ & î & $\stackrel{\overbrace{}}{\sim}$ & $\stackrel{2}{i}$ & $\underset{\stackrel{T}{T}}{\stackrel{\sim}{\sim}}$ & $\begin{array}{l}n \\
\sim \\
i\end{array}$ & in & $\underset{\partial}{\partial}$ & $\stackrel{ }{\stackrel{1}{i}}$ & $\begin{array}{l}\infty \\
\infty \\
-\end{array}$ & & & $\vec{ָ}$ \\
\hline & $\underset{4}{Z}$ & $\frac{\frac{\sqrt[0]{0}}{0}}{\frac{0}{0}}$ & 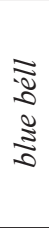 & 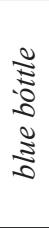 & 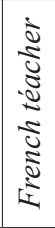 & 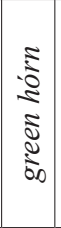 & 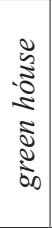 & 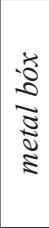 & 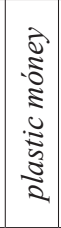 & 矛 & $\mid \begin{array}{l}3 \\
\vdots \\
0 \\
3 \\
2 \\
2\end{array}$ & & & \\
\hline & 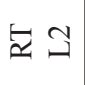 & $\underset{\dot{r}}{\stackrel{a}{q}}$ & $\stackrel{n}{a}$ & $\begin{array}{l}\infty \\
\infty \\
i\end{array}$ & $\begin{array}{l}0 \\
+ \\
i \\
\text { in }\end{array}$ & $\begin{array}{l}0 \\
n \\
n \\
n\end{array}$ & $\begin{array}{l}\infty \\
\infty \\
i\end{array}$ & $\begin{array}{l}\vec{b} \\
\dot{+}\end{array}$ & $\underset{\stackrel{g}{q}}{\stackrel{g}{r}}$ & $\underset{\stackrel{q}{+}}{i}$ & $\stackrel{\infty}{\stackrel{\infty}{-}}$ & & & $\vec{\theta}$ \\
\hline & $\vec{\simeq} \Xi$ & ते & $\begin{array}{l}\stackrel{+}{+} \\
i\end{array}$ & $\frac{a}{i}$ & $\begin{array}{l}J \\
i \\
ن\end{array}$ & $\begin{array}{c}\hat{\sigma} \\
\dot{r}\end{array}$ & $\begin{array}{l}\infty \\
0 \\
i\end{array} \mid$ & $\stackrel{+}{i}$ & $\begin{array}{l}\tilde{n} \\
\dot{m}\end{array}$ & $\vec{i}$ & $\stackrel{?}{\text { ? }}$ & & & $\stackrel{i}{i}$ \\
\hline & $\begin{array}{l}Z_{1} \\
\text { Z }\end{array}$ & 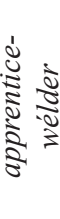 & 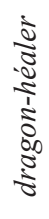 & 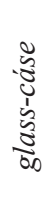 & 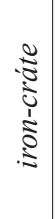 & 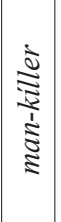 & 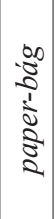 & 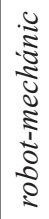 &  & 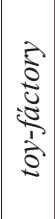 & $\mid \begin{array}{c}0 \\
0 \\
0 \\
0 \\
1 \\
1 \\
0 \\
0 \\
0 \\
3\end{array}$ & & & \\
\hline \multirow{6}{*}{ 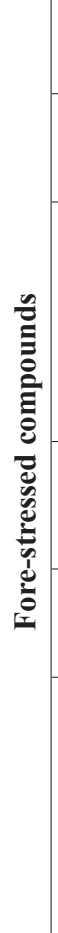 } & 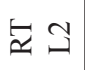 & $\stackrel{\infty}{\infty}$ & $\stackrel{\infty}{\stackrel{\infty}{\sim}}$ & $\stackrel{\vec{i}}{\vec{i}}$ & $\begin{array}{l}\vec{d} \\
\dot{i}\end{array}$ & $\begin{array}{l}O \\
i \\
i\end{array}$ & $\stackrel{\infty}{\stackrel{-}{q}}$ & $\underset{\dot{m}}{g}$ & $\hat{n}$ & & & & & $\frac{\infty}{i}$ \\
\hline & 公 コ & $\stackrel{\oplus}{\oplus}$ & $\frac{\partial}{i}$ & $\stackrel{\overbrace{}}{\sim}$ & $\underset{\stackrel{f}{\sim}}{\mathrm{i}}$ & $\stackrel{-}{\partial}$ & $\begin{array}{l}\infty \\
n \\
-\end{array}$ & $\stackrel{n}{n}$ & $\begin{array}{l}\infty \\
n \\
n\end{array}$ & & & & & $\stackrel{\infty}{\stackrel{\infty}{i}}$ \\
\hline & $\underset{4}{Z}$ & $\begin{array}{l}\frac{\pi}{0} \\
\frac{0}{0} \\
\frac{0}{0}\end{array}$ & 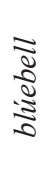 & 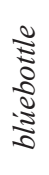 &  & 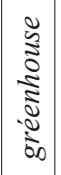 & 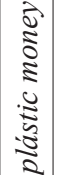 & 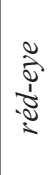 &  & & & & & \\
\hline & $\underline{\underline{a}}$ & $\underset{\forall}{\overrightarrow{+}}$ & $\stackrel{n}{m}$ & $\begin{array}{l}\stackrel{0}{\longrightarrow} \\
\dot{r}\end{array}$ & $\begin{array}{l}\widehat{\sigma} \\
i \\
i\end{array}$ & 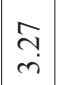 & $\begin{array}{l}0 \\
\infty \\
i \\
i\end{array}$ & $\stackrel{m}{i}$ & $\begin{array}{l}\infty \\
\infty \\
i\end{array}$ & $\vec{J}$ & $\begin{array}{c}\tilde{\sigma} \\
\dot{\sigma}\end{array}$ & $\stackrel{8}{8}$ & 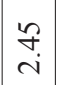 & है. \\
\hline & 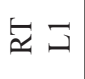 & $\stackrel{\dot{n}}{n}$ & $\frac{\infty}{i}$ & $\stackrel{9}{m}$ & $\stackrel{\vec{m}}{\mathrm{i}}$ & $\begin{array}{c}\tilde{O} \\
\dot{m}\end{array}$ & $\begin{array}{c}\stackrel{0}{n} \\
\text { in }\end{array}$ & $\stackrel{\sim}{\sim}$ & 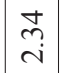 & $\stackrel{8}{6}$ & $\begin{array}{l}\infty \\
0 \\
\dot{0}\end{array}$ & $\underset{-}{\stackrel{f}{\sigma}}$ & 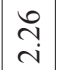 & חֶֶ, \\
\hline & $z_{1}$ & 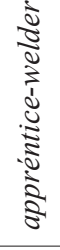 & 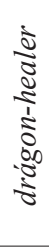 & 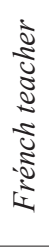 & 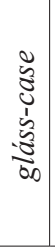 & $\mid \begin{array}{c}0 \\
0 \\
0 \\
1 \\
1 \\
0 \\
0\end{array}$ & 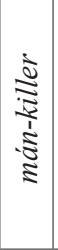 & 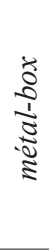 & 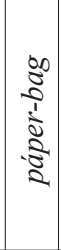 & 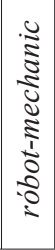 & $\left|\begin{array}{c}0 \\
0 \\
0 \\
\frac{2}{2} \\
5 \\
\frac{0}{1} \\
\frac{1}{2} \\
\frac{0}{2}\end{array}\right|$ & $\begin{array}{l}\overrightarrow{0} \\
\frac{1}{0} \\
\frac{0}{0} \\
\frac{1}{1}\end{array}$ & $\left|\begin{array}{c}5 \\
0 \\
0 \\
0 \\
0 \\
\vdots \\
\vdots \\
\vdots \\
-0 \\
\vdots \\
\vdots\end{array}\right|$ & $\sum_{\Sigma}^{\Xi}$ \\
\hline
\end{tabular}


In general, the results of L1s and L2s are comparable; there is no drastic discrepancy between these two subject groups in perceiving all types of constructs. Moreover, the results obtained by L1 subjects are in compatibility with previous studies in this area (cf. Zubizarreta et al., 2013), fundamentally that attributive constructions elicited more correct renditions than non-attributive ones.

To briefly recapitulate, opaque compounds in English are attributive and thus regularly fore-stressed. However, in the case of transparent compounds, we need to view them through the lens of a general algorithm resulting from attributiveness: attributive compounds are usually end-stressed and non-attributive are usually fore-stressed, with certain changeability due to analogy or lexicalization. This generalization for opaque compounds, tackled in (7), is clearly verified by our experiments: these were responded to most accurately across the board.

Following the discussion raised in Section 2 about the role of analogy, we can account for stress placement in A-N phrases by L2s. Namely, such phrases obtain a similar stress-pattern in Polish and English, i.e., the head N is stressed. A-N opaque compounds, on the other hand, are dissimilar in these languages because in Polish the rightmost component is stressed and in English the leftmost one. Yet in both cases it is the non-head that is stressed. The procedure adopted by L2s consists in placing the stress asymmetrically to their native language. Although the role of syntactic representation explains accuracy of stress recognition in A-N phrases among L2s, it is still an unsolved puzzle in the case of L1s.

This perplexing issue of $\mathrm{A}-\mathrm{N}$ phrases being identified so inaccurately, as shown in (8) above can be attributed to the model of English compound-phrase stress distinction put forward by Vogel and Raimy (2002), as shown in Figure 5.

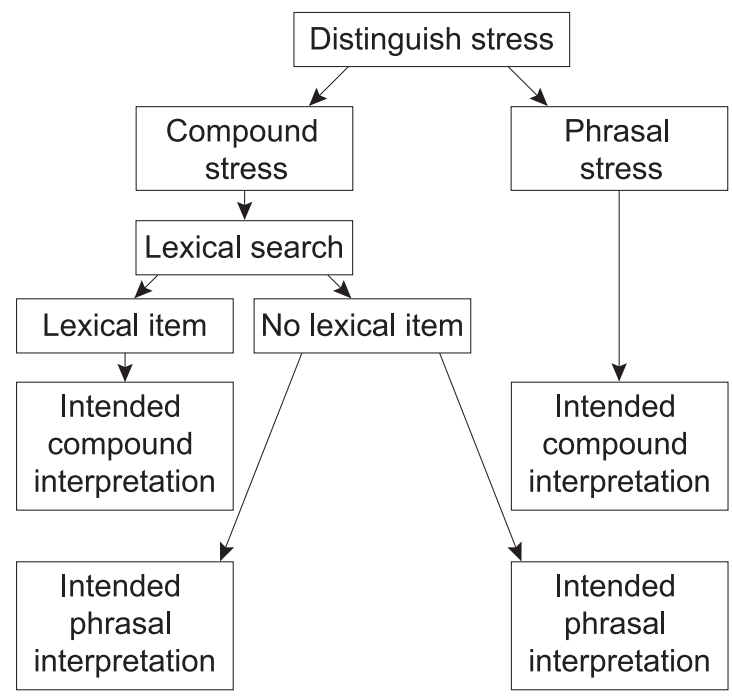

Figure 5. Vogel et al.'s model of stress distinction 
Their model was built on empirical studies which employed a picture-selection task, in which L1s heard one member of compound/phrase minimal-pairs and their task was to choose the correct picture: either a compound or a phrasal interpretation. We have developed our own model, yet consistent with our outcomes, on the basis of the one proposed by Vogel and Raimy.

According to the Vogel et al.'s model, when L1s hear an auditory stimulus they first distinguish the stress pattern and then they perform a lexical search. And even though they distinguish the pattern which is attributed to compounds, individual speakers may choose the default phrasal interpretation in the case when they do not find a lexical entry in the search (e.g., when the compound is not familiar). Although only about L1s, this model concerns the matter of compound/ phrase stress distinction: the key issue in the present paper.

Our model (Figure 6), on the other hand, provides a paradigm which distinguishes compound and phrasal stress in the case of promiscuous collocations for both L1s and L2s. The interpretation is selected on the basis of a lexical search in the speaker's mental lexicon. Whether an item, as a unified whole, is found or not affects the chosen interpretation. The default is always the one which is correct. Therefore, it is of a higher probability for L2s to store phrases as "chunks of language" than for L1s, who decompose rather than retrieve them from their mental lexicon. The same happens when a compound stress is encountered: A-N opaque compounds, as they are lexicalized units, are usually found in the mental lexicon and therefore associated with intended compound interpretation. The high accuracy of stress identification in A-N compounds thus results from the fact that the speakers could find these lexical units in their mental lexicon, both L1s and L2s.

It is then plausible to hypothesize that opaque A-N compounds would trigger most correct responses across the board as they are stored in the mental lexicon as unified wholes, unlike transparent $\mathrm{N}-\mathrm{N}$ compounds. Following this reasoning: it is easier for the speakers to assign the correct stress patterns to lexicalized items, as shown in (9).

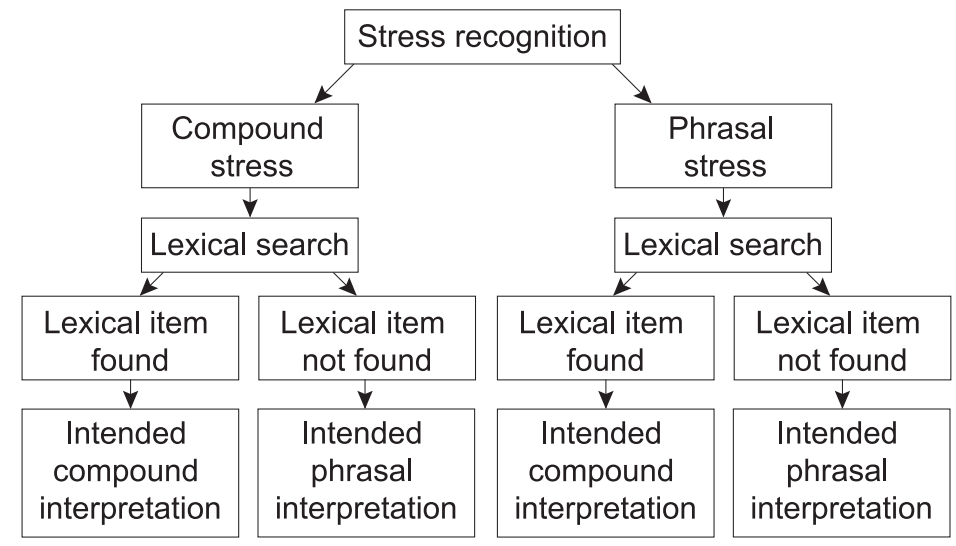

Figure 6. Model of compound and phrasal stress distinction in promiscuous collocations 
If the limited sample of compounds and phrases which were employed in our study is in any way a picture of L1s' production and perception of compounds and phrasal stress, it is not at all surprising that $\mathrm{L} 2 \mathrm{~s}$ have problems in coping with this vague distinction. In Polish the main stress in A-N phrases, which are head final, and in A-N compounds, which are head initial, is always on the rightmost constituent, which adds to the complexity of this particular aspect of SLA study. This implies that the main stress falls on $\mathrm{N}$, irrespectively of the internal relation entertained by the constituents. Faced with a high degree of promiscuity in the input, the Polish speakers of English use the prosodic pattern that corresponds to their native language - end-based stress. It is therefore reasonable to conclude that L2 acquisition of compounds requires a considerable amount of consistent data for the L2 learner to successfully imitate the target grammar.

\section{Conclusion}

Although there is an extensive body of work on SLA of the phonology of wordstress, relatively few studies investigated the acquisition of compound and phrasal stress in both production and perception. This somewhat neglected area offers an insight of the typical mistakes that L2 speakers make as well as of learning strategies that they develop. The results of the present research give some practical implications that may come in handy for both teachers and learners of English. The process of compound/phrasal stress acquisition should start from A-N opaque compounds (e.g., rédwood) - such forms are stored in the mental lexicon with their associated fore-stress pattern. Next, A-N compounds should be juxtaposed with A-N phrases (e.g., red wóod) to present the fore-stress vs. end-stress distribution, which in turn would possibly become the frequent point of reference for learners to out-compete the L1 grammar, which enforces end-stress pattern across the board. Only after acquiring the fore- and end-stress patterns in A-N collocations should we concentrate on the more structurally complicated constructs $-\mathrm{N}-\mathrm{N}$ compounds.

The results contribute to the current experimental research agenda on language interrelations between prosody and semantic transparency. A further consequence of the analysis is that the strength of the link between prosody and semantic transparency may vary with regard to the type of experiment: production or perception. Unlike in the production, the perception showed a relatively clear link which consists in placing end-stress for semantically transparent compounds and fore-stress for semantically opaque ones. The following additional implications for L2 speakers could be observed:

i) there is an overall tendency to produce fore-stress regardless of the item's classification, thus providing empirical support for Giegerich's claims;

ii) the Polish community can acquire English trochaic (leftmost) stress-patterns, which is a particularly significant advantage for Polish learners of English. 
The present paper has outlined some significant areas for future research on SLA. Certainly, there are many more problematic issues in this yet under-studied area of L2 acquisition. Our experiments should be treated as a pilot study which may offer an inspiration for linguists, who investigate SLA (possibly after certain reevaluation).

\section{References}

Almbark, R., N. Bouchhioua and S. Hellmuth. 2014. "Acquiring the phonetics and phonology of English word stress: Comparing learners from different L1 backgrounds." Concordia Working Papers in Applied Linguistics 5. 19-35.

Anusiewicz, P. 2010. Compound Words - a Semantic and Formal Classification and Productivity Analysis of Specific Word Formation Processes Found in English and Polish. Wrocław: University of Wrocław.

Archibald, J. 1994. "A formal model of learning L2 prosodic phonology." Second Language Research 10. 215-240.

Archibald, J. 1997. "The acquisition of English stress by speakers of nonaccentual languages: Lexical storage versus computation of stress." Linguistics 35. 167-182.

Bauer, L. 1998. "When is a sequence of two nouns a compound in English?" English Language and Linguistics 2. 65-86.

Bell, M.J. and M. Schafer. 2013. "Semantic transparency: Challenges for distributional semantics." Towards a formal distributional semantics: IWCS 2013 Workshop. Potsdam, Germany.

El-Bialy, R., C.L. Gagné and T.L. Spalding. 2013."Processing of English compounds is sensitive to the constituents' semantic transparency." The Mental Lexicon, 8.1. 75-95.

Flege, J.E. and O.S. Bohn. 1989. "An instrumental study of vowel reduction and stress placement in Spanish-accented English.” Studies in Second Language Acquisition 11. 35-62.

Ghazali, S. and N. Bouchhioua. 2003. "The learning of English prosodic structures byspeakers of Tunisian Arabic: Word stress and weak forms." Proceedings of the 15th International Congress of Phonetic Sciences.

Giegerich, H. 2006. "Attribution in English and the Distinction between Phrases and Compounds." In: Rösel, P. (ed.) Englisch in Zeit und Raum - English in Time and Space: Forschungsberichtfür Klaus Faiss. Trier: WissenschaftlicherVerlag Trier.

Jespersen, O. 1942. A Modern English Grammar on Historical Principles, Part VI: Morphology. London and Copenhagen.

Libben, G. 1998. "Semantic transparency in the processing of compounds: Consequences for representation, processing, and impairment." Brain and Language 61.1. 30-44.

Marchand, H. 1969. The Categories and Types of Present-day English Word Formation: A Synchronic-diachronic Approach. 2nd ed. Munchen.

Mennen, I., A. Chen and F. Karlsson. 2010. "Characterising the Internal Structure Of learner Intonation and Its Development over Time." In: Proceedings of New Sounds 2010: The Sixth International Syymposium on the Acquisition of Second Language Speech. University of Poznan.

Olsen, S. 2001. "Copulative compounds. A closer look at the interface between morphology and syntax." In: Booij G. and J. van Marle (eds.) Yearbook of Morphology 2000. Dordrecht, 279-320.

Szymanek, B. 2012. "IE Slavonic: Polish.” In: Lieber, R. and P. Štekauer (eds.) The Oxford Handbook of Compounding. Oxford: Oxford University Press, 464-477.

Traxler, M.J. 2012. Introduction to Psycholinguistics: Understanding Language Science. Cichester: Blackwell Publishing.

Vogel, I. and E. Raimy. 2002. "The acquisition of compounds vs. phrasal stress: The role of prosodic constituents." Journal of Child Language 29. 225-250. 
Zubizarreta, M.L., X. He and N. Jonckheere. 2013. "An L2 study on production of stress patterns in English compounds.” In: Becher, M., J. Rothman and B. Schwartz (eds.) Generative Linguistics and Acquisition: Studies in Honor of Nina Hyams. Amsterdam, Philadelphia: John Benjamins, 185-203.

Zubizarreta, M.L. and E. Nava. 2011. "Encoding discourse-based meaning: Prosody vs. syntax. Implications for Second Language Acquisition." Lingua 121.4. 652-659.

\section{Appendix \\ $\mathrm{N}-\mathrm{N}$ compounds and $\mathrm{A}-\mathrm{N}$ compounds/phrases}

- A heavily pregnant woman asked if there was any woman-doctor available. - If I have a choice between going to a man-doctor and a woman-doctor and they're both on the GP list, I will choose the woman, because the woman has had to work much harder to get at an equal level with the man.

- We visited a toy-factory located in the lush mountains of western North Carolina.

- When I was a child I used to share my toy-factory with my siblings.

- As soon as he found out how demanding this profession may be, Mark didn't want to be an apprentice-welder anymore because he had started to have problems with his eyesight caused by strong light emission.

- It was their boss's wish that Toby become reconciled with his younger colleague Jim. Both Toby and Jim are trainees in his company producing soft toys; he could be called an apprentice-welder; he is such a skilled peacemaker.

- How can a woman, who makes so many language mistakes in French, call herself a French teacher.

- Despite the fact that it's difficult to understand his English accent, everybody likes our new French teacher from Paris.

- Recently ten male bodies have been found - there must be some serial man-killer prowling the alleys of the city after dark.

- Several women have been accused of a recent murder, but after a closer investigation the culprit turned out to be a man-killer, not a woman-killer.

- The company has placed an ad in the newspaper in which they wanted to hire a very experienced robot-mechanic as there are instances galore of malfunctions of their machinery.

- It is predicted that in the future people will no longer have to care about their households as there will be a robot-mechanic that will take care of our household appliances. 
- Not only was Merlin a great sorcerer who fought evil forces but he was also a dragon-healer who helped his mythical friends to recover from severe wounds.

- When I was a child, my mother used to tell me a story about a huge fourlegged flying creature which could bring dead people to life; this creature was called a dragon-healer.

- These three steel containers by the wall contain various items: the two to the left can be moved without extra caution, but the last one, labelled "fragile", is a protective glass-case containing a precious collection of lab equipment.

- My grandmother always kept her gold jewellery in a wooden case; however, when she found out that woodworms had started to consume the case, she replaced it with a glass-case.

- A plastic bag which is used for storing rubbish made of paper can be confusingly called a paper-bag.

- A new distribution network provides free-of-charge paper-bags for customers who complain that the plastic bags tear very readily.

- The steelworks in Upper Silesia has run out of space for storing their products, although there are over ten steel-warehouses.

- My uncle's storage units have burnt down so now he wants to build a steel-warehouse which won't burst into flames that easily.

- The factory on the outskirts of the city produces special light crates made of wood for storing heavy iron things; these iron-crates come in handy.

- Despite the fact that the parcels were damaged, the transported products remained intact as they had been put into iron-crates.

- The board of supervisors placed a yellow plastic container into which residents of our district should throw their scrap metal; my dad was very pleased with the metal-box, saying that they had finally put an end to lawlessness.

- Johnny went to the attic to find a rusty metal-box in which he kept many heirlooms, such as old stamp albums and photographs of his ancestors.

- When I was a child, I liked playing with plastic money which resembled the real money.

- Owing to the development of technology, more and more people substitute cash for credit cards, also called plastic money.

- My uncle took photos of many kinds of birds among which were ravens, eagles, swallows, but he never managed to capture a blackbird. 
— Seldom can a stork be seen as a black bird as this breed is quite rare.

- One of the environmental pressures in the Great Barrier Reef includes cyclic population outbreaks of the bluebottles, which are a kind of jelly fish.

- Water is frequently sold in blue bottles as they make a lasting impression that the water is crystal clear and thirst-quenching.

- My mother had always wanted to have some place where she could grow plants so she had a greenhouse built.

- All my friends around me have got white houses, except for Mark who has a green house with a huge blue chimney.

- It is said that the biggest and oldest tree is a redwood, which grows, for instance, in California.

- A shop assistant showed me several kinds of tables, some of them made of light brown wood, dark brown wood and red wood.

- When my brother and I were children, our mother used to give us garlands made of bluebells.

- Three years ago I visited a church with an unusual and beautiful blue bell hanging at the top of a very tall tower.

- I hate alcohol, especially cheap; that's why I never drink red-eye, which is a kind of cheap whiskey.

- I am allergic to cats, so when I'm too close to one, I've got red eyes.

- It took me a while, as an inexperienced worker, to get the hang of the rules everybody in the company called me a greenhorn.

- I've just read a book about a man whose weapon was a green horn with spikes.

Filler sentences

- I wanted to surprise my wife so I went to a watchmaker and asked him to repair her old heirloom.

- I turned the tap and reached for the soap-dispenser to wash my hands.

- Arriving in New York, I encountered a very talkative taxi-driver.

- I love drinking orange juice for breakfast as it contains several essential vitamins.

- We put aside some money so we could buy a state-of-the-art dishwasher.

- She reminded him of a sunflower turned toward the light.

- My uncle has broken his backbone and he has to use a wheelchair to move. 
- When I went to the Netherlands, what struck me was the huge number of windmills.

- My little nephew dreams about meeting a reindeer with massive antlers and a red nose.

- When I was scuba-diving in the ocean, I saw many species of fish, several jellyfish and a tiny seahorse.

— Last week I went into the mountains where I saw a spring with crystal clear water.

- When I went window-shopping, I noticed a beautiful yellow shirt which was perfectly suitable for me.

- I am always touched by films based on life-stories showing events from the first World War.

- At last we came to the head of the winding white slope just to ski.

- Strangely enough, the most basic human values differ significantly among city raised people.

- She was surprised because the room he had been given was lily-white.

- Despite the fact that her cocktail dress looked expensive, it turned out to be dirt cheap.

- There are only three ways to fix a public debt crisis: raise taxes, cut spending, or find a sugar daddy.

- It was hard to go through the meadow with waist-high grass.

- Take some water in this plastic bucket as we might later need it for washing. 